\title{
ASSESSMENT OF NURSES' PERFORMANCE RELATED TO CONTROL OF SOME PARASITES ACQUIRED FROM FRESH VEGETABLES AS A PATIENT SAFETY MEASURE IN A MILITARY HOSPITAL

\author{
By
}

AHMED MEGAHED AHMED SALEH ${ }^{1}$, HISHAM ABD EL-RAOUF ALI ${ }^{2}$, SALWA ABDALLA MOHAMED AHMED ${ }^{3}$, NAGLAA ELSAID MOHAMED ${ }^{4}$ AND TOSSON A. MORSY ${ }^{5}$

Military Institute of Health and Epidemiology ${ }^{1,3,4}$ and Medical Surgical Nursing ${ }^{3}$, The Military Medical Academy ${ }^{1,2,3,4}$ and Department of Parasitology, Faculty of Medicine, Ain Shams University, Cairo $11566^{5}$, Egypt

\begin{abstract}
Foodborne parasitic infection in the hospital constitutes a major health problem particularly for patients who are more vulnerable than healthy subjects to parasitic risks. Parasitic infection represents an area of concern for advanced practice nurse. The work assessed the military nursing staff performance regarding the nosocomial food-borne parasitic infection control. Subjects and Methods: Research design; A descriptive research design was used to identify knowledge, attitudes and practice of nurses related to nosocomial food-borne parasitic infection control measures. Setting: The study was conducted at a general military hospital. Subjects: 50 nurses, the whole available number who covered the inclusion criteria. Data collection tools: It included; (1): Structured interview sheet was constructed after reviewing the relevant literature to elicit information, it included two parts a) subjects' sociodemographic characteristics b) nurses' knowledge regarding nosocomial parasites infections. (2): Rating scale: to assess attitude of nursing staff towards nosocomial parasites infections and its prevention. (3): Observational Checklist: to assess the nurses' practice of self-protection and control of nosocomial parasitic infections control measures. Results: A statistically insignificant difference between knowledge levels about nosocomial parasites infection among military nurses. More than half of participant nurses had positive attitude towards nosocomial parasite infection control and prevention without significant difference between all topics $(\mathrm{P}>0.056)$. That most participant nurses had unsatisfactory practice to infection control measures with significant lower score for procurement, storage and preparation of raw material followed by personal hygiene $(\mathrm{P}<0.05)$. Recommendations: Nurses in all roles and settings can demonstrate leadership in infection prevention and control by using their knowledge, skill and judgment to initiate appropriate and immediate infection control procedures.
\end{abstract}

Key words: Parasites' infection control, Military hospital, Patients safety measure.

\section{Introduction}

Nosocomial infection also called "hospital acquired infection" or "the healthcare associated infection" can be defined as an infection acquired in hospital by a patient who was admitted for a reason other than that infection. Nosocomial infections are commonly caused by bacteria. Nosocomial infections can also be caused by viruses, fungi, and parasites (Weinstein, 2004; Kouchak and Askarian, 2012). Most studies of the incidence of nosocomial infections ignore parasitic infections. Based on data from 1,265 intensive care units in 75 countries, it was found that the proportion of parasites in nosocomial infections was $0.48 \%$ overall, and $0.25 \%$ in Western Europe (Vincent et al, 2009).

Nosocomial infections represent an increasing threat to public health. In most cases, they concern patients with risk factors such as taken radio- and chemotherapy, those whose immune system might be suppressed and those who might be HIVpositive. Intestinal parasites are frequently recorded among patients after chemotherapy, steroid therapy and long-term antibiotic therapy against bacteria, and therefore may 
affect the patients in oncological, intensive care, internal medicine, geriatric and pediatric wards (El-Sibaei et al, 2006).

An analysis of the available literature also indicates an increase in the number of hospital parasitizes. More travel is taking place to areas endemic for many species of parasites and consequently, symptoms of infection are reported upon returning, sometimes even years later. As these patients are admitted to hospital where in many cases, they can be a source of infection to others, it seems reasonable to extend the list of emergency factors to include parasites such as the Plasmodium, Toxoplasma and Trypanosoma. Also, noteworthy are the mites and insects that can live on the human skin and inhabit the hospital environment. Their activity, and the microorganisms that colonize them, can pose a threat to people weakened or immunosuppressed with chemotherapy or longterm antibiotic therapy (Goralska and Kurnatowski, 2013).

The parasitic infections represent an area of concern for advanced practice nurses, particularly those working in rural areas or urban environments populations and those caring for patients with immunodeficiencyrelated diseases. Zoonotic protozoa increasing in prevalence because of poor sanitation, overcrowding, increased foreign travel, and high-risk sexual behaviors. There is a need for public education to promote awareness and prevention of such infections. This emerging public health problem has been reported sporadically in the medical and prenatal nursing literature (Marecki et al, 1997).

The food hygiene in the hospital can acquire peculiar features: indeed, many patients could be more vulnerable than healthy subjects to microbiological and nutritional risks; large numbers of persons can be exposed to infections and possible complications; gastroenteritis can impair digestion and absorption of nutrients and the perception or fear about poor food hygiene practices might result in patients rejecting the meals supplied by the hospital catering (Buccheri et al, 2007). In nosocomial outbreaks of infectious intestinal disease, the mortality risk has been proved to be significantly higher than the community outbreaks and highest for foodborne outbreaks. On the other hand, further peculiar concern arises from the common involvement in the role of food handlers of nurses or domestic staff, who are not specifically trained about food hygiene and (hazard analysis and critical control point) HACCP, but can be engaged in receipt, distribution and serving of ready-made foods and supervision of these services (Lazarević et al, 2013).

As a health professional, nurses should have appropriate knowledge about food safety. The importance of safe food for hospitalized patients and the detrimental effect that contaminated food could have on their recovery has been widely emphasized. Food safety in the hospital may have unique features; many patients are more vulnerable than healthy subjects to microbiological and nutritional risk. Larger numbers of patients can be exposed to infection and possible complications. Further concern arises from the common use of nurses as food handlers as they are not specifically trained about food hygiene but cane engaged in the distribution and serving of readymade foods and supervision of these services, so the prevention of foodborne diseases requires all food consumers, especially nurses to be thought about food handling (Sanlier et al, 2012).

Many Nosocomial helminthes parasites acquired from not well washed green salad or raw fruits (Minta et al, 2007) and protozoa (Vicente et al, 2012)

The selected foodborne parasites were 1Fascioliasis caused by Fasciolia gigantica or $F$. hepatica, infective is encysted metacercaria (Rashed et al, 2010), 2-Ascariasis caused by Ascaris lumbricides, infective stage is mature embryonated egg (El Fakahany et al. (2013), 3- Enterobiasis caused by Enterobius vermicularis, infective stage is eggs (El Fakahany et al. (2013). 4- Hydatidosis 
caused by ingestion of eggs dropped from dogs harboring Echinococcus granulosus (El Kady et al, 2011). The selected protozoa were: 1- Amoebiasis caused by Entameba histolytica, infective stage is four nucleated cyst (El Shazly et al, 2007). 2- Giardiasis caused by Giardia lamblia, infective stage is four nucleated cyst (El Shazly et al, 2004).

\section{Subjects and Methods}

The work aims to assess the military nursing staff performance regarding nosocomial food-borne parasites' infection control, concerning parasites acquired from not well washed green vegetables and suggest recommendations to improve quality of care and patient safety in this regards.

Objectives: 1- To assess the military nursing staff knowledge and attitude as regard parasites' infection control, concerning parasites acquired from not well washed green vegetables and raw fruits. 2- To evaluate the military nursing staff practice regarding parasites' infection control as a patient safety measures. 3- To suggest recommendations for better means of nosocomial food-borne parasitic infection prevention and control measures.

Research design: A descriptive research design was used to identify knowledge, attitudes and practice of nurses related to nosocomial food-borne parasitic infection control measures.

Setting: The study was conducted at a General Military Hospital. All the military nursing staff that accepted to participate in the research and met the inclusion criteria (accepting to participate in the research and has experience more than one year as a nursing staff member) was selected.

Data collection tools: Three tools were constructed after reviewing the relevant literature to illicit information, it included: (Tool 1): Structured interview sheet that concerned with a) subjects' sociodemographic characteristics to gather data related to age, educational level, years of experience, marital status, working departments and their previous training regarding preven- tion of nosocomial parasites' infections b) to collect data related to nursing staff level of knowledge about nosocomial parasites infections such as epidemiology, causes, population at risk clinical picture, complication, infection control and preventive measure regarding nosocomial parasites' infections. Scoring system for knowledge questions was as follow:

The correct answer took 1 degree. Incorrect answer took 0 (zero) degree.

Then nurses knowledge score percent were classified into knowledge levels as follow: 1 - score of $<60 \%$ was considered (fail), 2score of 60- 70 was considered (pass), 3score of 70- 80 was considered (good), 4score of 80- 90 was considered (very good) and 5- score of 90 or more was considered (excellent). Tool (2): Rating scale: to assess attitude of nursing staff towards nosocomial parasites' infections control and prevention. Scoring system for attitude statements was 1 degree for agree (positive attitude) and zero for disagree or uncertain (negative attitude). Tool (3): Observational Checklist: It was used to assess the nurses' practice regarding nosocomial parasitic infections control measures. Scoring system for practice items was 1 degree for correctly done and zero for not correctly done or not done.

Validity Test: Developed questionnaires \& checklist was submitted to a panel of three experts in the field of nursing education, epidemiology and infection control for content language clarity, relevancy, and readability, ease of understanding, question sequence, and completion time. Questionnaires and checklist were edited after experts' suggestions.

Reliability of the Instruments: For research purpose, reliability test was done on scientific bases.

Data collection procedure: An official permission was obtained from the Director of the Military Hospital, as well as from the nursing director. Informed verbal consents were obtained from each subject before participation in the study. Each nursing staff 
was informed about the nature and purpose of the study. Total confidentiality of any obtained information was ensured. Data collection procedure started at the beginning of May 2014 till end of August2014.

Statistical analysis: Data entry and statistical analysis were done using SPSS 20.0 statistical software package. Data was presented using descriptive statistics in the form of frequencies and percentages for qualitative variables, and means and standard deviations for quantitative variables. The qualitative categorical variables were compared using chi-square or Fisher exact test as suitable. Quantitative variables were analyzed using Student t-test. Statistical significance is set at $p$-value $<0.05$.

\section{Results}

Table I: Nurses' socio-demographic characteristics $(\mathrm{N}=50)$

\begin{tabular}{|c|c|c|c|c|}
\hline Characteristics & No. & $\%$ & $\chi^{2}$ test & $\mathrm{P}$ value \\
\hline Age: $<20$ years & 10 & 20.0 & \multirow{3}{*}{17.5} & \multirow{3}{*}{$0.00015^{* *}$} \\
\hline $20-30$ years & 28 & 56.0 & & \\
\hline More than 30 years & 12 & 24.0 & & \\
\hline Descriptive Statistics & \multicolumn{2}{|c|}{$28.23 \pm 6.79$} & \multicolumn{2}{|c|}{ Range $(19.0-44.0)$} \\
\hline Males & 15 & 30.0 & \multirow[b]{2}{*}{16.0} & \multirow[b]{2}{*}{$0.000 * *$} \\
\hline Females & 35 & 70.0 & & \\
\hline Marital status: Single/divorced & 22 & 44.0 & \multirow[b]{2}{*}{26.2} & \multirow[b]{2}{*}{$0.000 * *$} \\
\hline Married & 28 & 56.0 & & \\
\hline Education :Bachelor Degree & 12 & 25.0 & \multirow{3}{*}{17.5} & \multirow{3}{*}{$0.0001 * *$} \\
\hline Technical Institute of Nursing & 10 & 22.5 & & \\
\hline Diploma & 28 & 52.5 & & \\
\hline *Attended infection control training course & 20 & 40.0 & \multirow[b]{2}{*}{8.53} & \multirow[b]{2}{*}{$0.003 * *$} \\
\hline Not attended & 30 & 60.0 & & \\
\hline Years of Experience: $<5$ years & 13 & 26.0 & \multirow{3}{*}{18.1} & \multirow{3}{*}{$0.000 * *$} \\
\hline 5-10years & 28 & 53.3 & & \\
\hline More than 10years & 9 & 18.0 & & \\
\hline Descriptive Statistics & \multicolumn{2}{|c|}{$9.43+3.87$} & \multicolumn{2}{|c|}{ Range $(3.00-18.00)$} \\
\hline Department: Medical & 21 & 42.0 & \multirow{3}{*}{3.7} & \multirow{3}{*}{0.16} \\
\hline Surgical & 17 & 34.0 & & \\
\hline Emergency/ICU & 12 & 24.0 & & \\
\hline
\end{tabular}

Table 2: Knowledge grades of nurses as regard nosocomial parasites $(n=50)$.

\begin{tabular}{|l|l|l|l|l|}
\hline Knowledge Grades & No & $\%$ & $\chi^{2}$ test & P value \\
\hline Fail $(<60 \%)$ & 22 & 44.0 & & \\
\cline { 1 - 3 } Pass $(60-70 \%)$ & 20 & 40.0 & \multirow{3}{*}{56} & \multirow{2}{*}{$0.000 * *$} \\
\cline { 1 - 3 }$(70-80 \%)$ & 8 & 16.0 & & \\
\cline { 1 - 3 } Very Good $(80-90 \%)$ & 0 & 0.0 & & \\
\hline Excellent $(>90 \%)$ & 0 & 0.0 & & \\
\hline
\end{tabular}

$* *$ Highly statistically significant at $\mathrm{p}<0.01$

Table 3: Nurses' attitude towards nosocomial parasitic infection $(n=50)$.

\begin{tabular}{|c|c|c|c|c|c|c|}
\hline \multirow{2}{*}{ Items } & \multicolumn{2}{|c|}{ +ve attitude } & \multicolumn{2}{|c|}{-ve attitude } & \multirow{2}{*}{$X^{2}$} & \multirow{2}{*}{$\mathrm{p}$-value } \\
\hline & No. & $\%$ & No. & $\%$ & & \\
\hline Dealing with suspected cases & 19 & 38.0 & 31 & 62.0 & \multirow{11}{*}{10.8} & \multirow{11}{*}{0.215} \\
\hline Measures for defined cases & 21 & 42.0 & 29 & 58.0 & & \\
\hline Regular investigations for at risk & 20 & 40.0 & 30 & 60.0 & & \\
\hline Importance of food hygiene & 27 & 54.0 & 23 & 46.0 & & \\
\hline Precautions for animal raising & 25 & 50.0 & 25 & 50.0 & & \\
\hline Importance of hand hygiene & 28 & 56.0 & 22 & 44.0 & & \\
\hline Importance of parasitic infection training programs & 18 & 36.0 & 32 & 66.0 & & \\
\hline Wearing gloves during patient handling. & 24 & 48.0 & 26 & 52.0 & & \\
\hline Precautions for eating fresh vegetables & 29 & 58.0 & 21 & 42.0 & & \\
\hline Importance of infection control measures & 23 & 46.0 & 27 & 54.0 & & \\
\hline Total & 27 & 54.0 & 23 & 46.0 & & \\
\hline
\end{tabular}


Table 4: Relationship between total knowledge percent score \& nurses' sociodemographic characteristics:

\begin{tabular}{|c|c|c|c|c|}
\hline \multicolumn{3}{|c|}{ Socio-demographic characteristics } & \multirow[t]{2}{*}{ Test } & \multirow[t]{2}{*}{$\mathrm{P}$} \\
\hline Mean $\pm \mathrm{SD}$ & Mean \pm SD & Mean \pm SD & & \\
\hline \multicolumn{5}{|c|}{ Nurses’ Age Groups } \\
\hline$<20 \mathrm{Y} \quad(\mathrm{n}=10)$ & $20-30 Y \quad(n=28)$ & $>30 Y(n=12)$ & ANOVA & $\mathrm{P}$ \\
\hline $52.34 \pm 7.55$ & $53.83 \pm 6.24$ & $58.65 \pm 7.21$ & 0.319 & 0.728 \\
\hline Male $(n=15)$ & \multicolumn{2}{|l|}{ Female $(n=35)$} & t-test & $\mathrm{P}$ \\
\hline $52.94 \pm 6.94$ & \multicolumn{2}{|l|}{$58.32 \pm 7.92$} & 1.892 & $0.031 *$ \\
\hline \multicolumn{5}{|c|}{ Nurses' Marital Status } \\
\hline Single $(n=18)$ & Married $(n=28)$ & Divorced/Widow $(\mathrm{n}=4)$ & ANOVA & $\mathrm{P}$ \\
\hline $53.56 \pm 7.94$ & $58.31 \pm 7.24$ & $52.36 \pm 8.22$ & 2.144 & $0.035^{*}$ \\
\hline \multicolumn{5}{|c|}{ Nurses' Education } \\
\hline Bachelor Degree $(n=12)$ & Technical Institute $(\mathrm{n}=10)$ & School Diploma $(n=28)$ & ANOVA & $\mathrm{P}$ \\
\hline $58.82 \pm 8.19$ & $53.13 \pm 7.13$ & $52.33 \pm 7.01$ & 3.173 & $0.049^{*}$ \\
\hline \multicolumn{5}{|c|}{ Attending previous courses } \\
\hline Attended $(n=20)$ & \multicolumn{2}{|l|}{ Not attended $(n=30)$} & t-test & $\mathrm{P}$ \\
\hline $51.2 \pm 10.05$ & $56.11 \pm 9.23$ & & 0.321 & $0.762 *$ \\
\hline \multicolumn{5}{|c|}{ Nurses' Years of Experience } \\
\hline$<5 Y(n=13)$ & $5-10 Y(n=28)$ & $>10 Y(n=9)$ & ANOVA & $\mathrm{P}$ \\
\hline $54.03 \pm 11.97$ & $55.95 \pm 8.03$ & $58.97 \pm 7.14$ & 1.918 & 0.156 \\
\hline \multicolumn{5}{|c|}{ Working Department } \\
\hline Medical $(n=21)$ & Surgical $(n=17)$ & Emergency/ICU $\quad(n=12)$ & ANOVA & $\mathrm{P}$ \\
\hline $55.33 \pm 9.55$ & $56.03 \pm 8.32$ & $55.87 \pm 8.84$ & 1.632 & 0.237 \\
\hline \multicolumn{3}{|c|}{ Total (Mean \pm SD) } & $56.44 \pm 9.6$ & \\
\hline
\end{tabular}

Table 5: Relationship between nurses' attitudes towards nosocomial parasitic infection \& sociodemographic characteristics.

\begin{tabular}{|c|c|c|c|c|c|}
\hline \multicolumn{4}{|c|}{ Socio-demographic characteristics } & \multirow[b]{2}{*}{ Test } & \multirow[b]{2}{*}{ P-value } \\
\hline Mean \pm SD & Mean \pm SD & & Mean \pm SD & & \\
\hline \multicolumn{6}{|c|}{ Nurses' Age Groups } \\
\hline$<20 Y(n=10)$ & \multicolumn{2}{|l|}{$20-30 Y(n=28)$} & $>30 Y(n=12)$ & ANOVA & $\mathrm{P}$ \\
\hline $51.22 \pm 9.32$ & \multicolumn{2}{|l|}{$52.43 \pm 8.43$} & $55.05 \pm 8.43$ & 0.632 & 0.657 \\
\hline \multicolumn{2}{|l|}{ Male $(n=15)$} & \multicolumn{2}{|c|}{ Female $(n=35)$} & t-test & $\mathrm{P}$ \\
\hline $53.45 \pm 6.77$ & & \multicolumn{2}{|c|}{$56.83 \pm 7.77$} & 1.875 & $0.048 *$ \\
\hline \multicolumn{6}{|c|}{ Nurses' Marital Status } \\
\hline Single $(n=18)$ & \multicolumn{2}{|l|}{ Married(n=28) } & Divorced/Widow $(n=4)$ & ANOVA & $\mathrm{P}$ \\
\hline $52.86 \pm 7.01$ & \multicolumn{2}{|l|}{$55.77 \pm 7.93$} & $53.21 \pm 8.74$ & 2.144 & $0.042 *$ \\
\hline \multicolumn{6}{|c|}{ Nurses' Education } \\
\hline Bachelor Degree $(n=12)$ & $\begin{array}{l}\text { Technical } \\
(\mathrm{n}=10)\end{array}$ & Institute & $\begin{array}{ll}\text { School Diploma } \\
(\mathrm{n}=28)\end{array} \quad$ & ANOVA & $\mathrm{P}$ \\
\hline $55.65 \pm 8.89$ & $53.54 \pm 7.76$ & & $51.98 \pm 7.95$ & 1.984 & $0.037 *$ \\
\hline \multicolumn{6}{|c|}{ Attending previous courses } \\
\hline \multicolumn{2}{|l|}{ Attended $(n=20)$} & \multicolumn{2}{|c|}{ Not attended $(n=30)$} & t-test & $\mathrm{P}$ \\
\hline $53.45 \pm 10.32$ & & \multicolumn{2}{|c|}{$54.54 \pm 9.87$} & 2.403 & 0.432 \\
\hline \multicolumn{6}{|c|}{ Nurses' Years of Experience } \\
\hline$<5 Y(n=13)$ & \multicolumn{2}{|l|}{$5-10 Y(n=28)$} & $>10 \mathrm{Y}(\mathrm{n}=9)$ & ANOVA & $\mathrm{P}$ \\
\hline $52.87 \pm 10.43$ & \multicolumn{2}{|l|}{$54.85 \pm 9.43$} & $55.07 \pm 9.54$ & 0.887 & 0.213 \\
\hline \multicolumn{6}{|c|}{ Work Department } \\
\hline $\operatorname{Medical}(n=21)$ & \multicolumn{2}{|l|}{ Surgical $(n=17)$} & Emergency/ICU $(n=12)$ & ANOVA & $\mathrm{P}$ \\
\hline $53.84 \pm 9.46$ & \multicolumn{2}{|l|}{$55.87 \pm 8.21$} & $53.76 \pm 8.32$ & 0.945 & 0.167 \\
\hline \multicolumn{4}{|l|}{ Total $($ Mean \pm SD $)$} & & \\
\hline
\end{tabular}


Table 6: Nurses' practice related to parasitic infection control measures $(\mathrm{N}=50)$

\begin{tabular}{|c|c|c|c|c|c|c|}
\hline \multirow[t]{2}{*}{ Items } & \multicolumn{2}{|c|}{ Appropriate } & \multicolumn{2}{|c|}{ Inappropriate } & \multirow{2}{*}{$\mathrm{X}^{2}$} & \multirow[b]{2}{*}{$P$ value } \\
\hline & No. & $\%$ & No. & $\%$ & & \\
\hline 1.Procurement of Raw Material & 15 & 30.0 & 35 & 70.0 & \multirow{12}{*}{17.9} & \multirow{12}{*}{$0.021 *$} \\
\hline 2. Storage of Raw Materials & 17 & 34.0 & 33 & 66.0 & & \\
\hline 3.Preparation of raw materials & 18 & 36.0 & 32 & 64.0 & & \\
\hline 4. Utensils \& Equipments & 25 & 50.0 & 25 & 50.0 & & \\
\hline 5. Cleaning \& Hygiene of establishment & 26 & 52.0 & 24 & 48.0 & & \\
\hline 6. Cleaning \& Hygiene of surrounding/ environment & 31 & 62.0 & 19 & 38.0 & & \\
\hline 7. Lighting facility & 20 & 40.0 & 30 & 60.0 & & \\
\hline 8. Garbage disposal facility & 22 & 44.0 & 28 & 56.0 & & \\
\hline 9. Pest control & 21 & 42.0 & 29 & 66.0 & & \\
\hline 10. Facilities for Personal Hygiene & 23 & 46.0 & 27 & 54.0 & & \\
\hline 11. Personal Hygiene & 17 & 34.0 & 33 & 56.0 & & \\
\hline Total & 20 & 40.0 & 30 & 60.0 & & \\
\hline
\end{tabular}

Table 7: Relationship between total nurses' practices score of infection control measures \& sociodemographic characteristics:

\begin{tabular}{|c|c|c|c|c|}
\hline Mean \pm SD & Mean \pm SD & Mean \pm SD & Test & $\mathrm{P}$ value \\
\hline \multicolumn{5}{|c|}{ Nurses' Age Groups } \\
\hline$<20 Y(n=10)$ & $20-30 Y \quad(n=28)$ & $>30 Y(n=12)$ & ANOVA & $\mathrm{P}$ \\
\hline $40.56 \pm 9.98$ & $41.56 \pm 8.78$ & $41.21 \pm 8.65$ & 0.632 & 0.657 \\
\hline Male $(n=15)$ & \multicolumn{2}{|l|}{ Female $(n=35)$} & t-test & $\mathrm{P}$ \\
\hline $40.52 \pm 8.66$ & \multicolumn{2}{|l|}{$41.94 \pm 8.12$} & 0.983 & 0.872 \\
\hline \multicolumn{5}{|c|}{ Nurses' Marital Status } \\
\hline Single $(n=18)$ & Married $(n=28)$ & Divorced/Widow $(n=4)$ & ANOVA & $\mathrm{P}$ \\
\hline $39.21 \pm 8.76$ & $41.83 \pm 8.21$ & $40.76 \pm 8.99$ & 2.144 & 0.287 \\
\hline \multicolumn{5}{|c|}{ Nurses' Education } \\
\hline Bachelor Degree $(n=12)$ & Technical Institute $(\mathrm{n}=10)$ & School Diploma $(n=28)$ & ANOVA & $\mathrm{P}$ \\
\hline $41.21 \pm 8.22$ & $40.21 \pm 7.89$ & $41.98 \pm 7.33$ & 1.984 & $0.043 *$ \\
\hline \multicolumn{5}{|c|}{ Attending previous courses } \\
\hline Attended $(n=20)$ & \multicolumn{2}{|l|}{ Not attended $(n=30)$} & t-test & $\mathrm{P}$ \\
\hline $40.21 \pm 10.77$ & \multicolumn{2}{|l|}{$40.87 \pm 9.43$} & 1.554 & 0.432 \\
\hline \multicolumn{5}{|c|}{ Nurses' Years of Experience } \\
\hline$<5 Y(n=13)$ & $5-10 Y(n=28)$ & $>10 Y(n=9)$ & ANOVA & $\mathrm{P}$ \\
\hline $40.07 \pm 10.54$ & $41.11 \pm 9.65$ & $42.92 \pm 9.23$ & 0.887 & $0.023 *$ \\
\hline \multicolumn{5}{|c|}{ Working Department } \\
\hline Medical $(n=21)$ & Surgical $(n=17)$ & Emergency/ICU $(\mathrm{n}=12)$ & ANOVA & $\mathrm{P}$ \\
\hline $39.23 \pm 9.12$ & $41.33 \pm 7.98$ & $42.08 \pm 8.76$ & 0.945 & 0.167 \\
\hline \multicolumn{2}{|l|}{ Total $($ Mean \pm SD $)$} & \multicolumn{2}{|c|}{$(40.11 \pm 8.09)$} & \\
\hline
\end{tabular}

\section{Discussion}

In the present study, $>50 \%$ of participants were in age category $20-30$ years, $70.0 \%$ of them were females, of which $>50 \%$ were married, and $52.5 \%$ were carried nursing school diploma, $40 \%$ attended infection control courses but none of them attended food safety or parasitic infection control training program, $53.3 \%$ of them have $5-10$ years' working experience, and $42.0 \%$ were from medical departments, $34.0 \%$ were from surgical departments and $24.0 \%$ were from high pressure areas. Evaluation of the training program on nosocomial food parasites $44.0 \%$ failed, $40 \%$ passed and $16 \%$ got good scores with high significant difference $(\mathrm{P}<0.01)$. Nurses in age group $>30$ years got the highest total mean \% Knowledge Score. Those carried Bachelor Degree of Nursing got highest total mean \% knowledge score. Nurses with working experience more than ten years got highest total mean \% knowledge score, with significant difference between total mean knowledge \% score ac- 
cording to sex, education, previous training courses and marital status $(\mathrm{P}<0.05)$. Also, nurses had positive attitude towards nosocomial parasite control and prevention but, without significant difference between all items $(\mathrm{P}>0.05)$. Moreover, nurses in the age group > 30years got highest total mean \% attitude score than other age groups and Nurses carried Bachelor Degree of Nursing have got the highest total mean \% attitude Score. Also, nurses with work experience $>$ 10 Years got highest total mean \% attitude score, with significant difference between total mean attitude \% score according to sex, education, and marital status $(\mathrm{P}<0.05)$. Besides, most of the participants had inappropriate practice of infection control measures with significant lower score for procurement, storage and preparation of raw material followed by personal hygiene $(p<0.05)$.

Generally speaking, the patient safety is a discipline in the health care sector that applies safety science methods toward the goal of achieving a trustworthy system of health care delivery. Patient safety is also an attribute of health care system; it minimizes the incidence and impact of and maximizes recovery from adverse events, adverse medical events are widespread and include infection (Leach, 2014). All health care professional including nurses are responsible for ensuring patient safety (Ashton, 2014).

On the other hand, Bertran et al. (2014) reported that even the trolley food waste generation was a practice embedded within the limitations related to the procedures of meal ordering, which included portion size choices and delivery, communication, tools for menu information, portioning and monitoring of food waste, as well as use of unserved food. They concluded that positive changes to these can be a way forward to develop strategies to reduce trolley food waste at the ward level.

In the present study, regarding the sociodemographic characteristics of nurses, those $>50 \%$ were in the age category $20-30$ years, with a high statistically significant differ- ence between them as regard age categories $(\mathrm{P}<0.001)$. Ages ranged from (19-44) and the mean for participants' ages was $28.23 \pm 6.79$. A total of $70.0 \%$ of them were females; with a highly statistically significant difference as regards sex $(\mathrm{P}<0.01) \ldots$ The participants $(42.0 \%)$ were from medical departments, $(34.0 \%)$ from surgical departments and (24.0\%) were from Emergency \& ICU departments; without significant difference between them as regard working department $(\mathrm{P}>0.05)$. Moreover, 53.3\% of them have 5-10 years' work experience; with statistically significant difference between them as regard work experience $(\mathrm{P}<0.01)$. Their working experience ranged from (3.00-18.00years) with a mean of $9.43 \pm 3.87$ years. Also, the nurses, $25.0 \%$ were University graduated, $22.5 \%$ have Technical Institute Nursing Diploma and 52.5\% have Nursing School Diploma with a highly significant difference between them as regard education $(\mathrm{P}<0.01)$.

Alabaster (2007) reformed nurse education, service modernization and changing roles have modified traditional views of nursing older people but not overturned them. El-Jardali et al. (2013) in Lebanon stated that the Lebanese nursing workforce shortages in difficult-to-staff areas have implications not only for quality of care but also for the whole population health outcomes, and that the marriage was positively associated with intent to stay in Lebanon and Jordan whereas years of experience were positively significant for Lebanon and Yemen. Mutale et al. (2013) in Zambia accounted men in nursing as equal to $6.6 \%$. Saleh et al. (2014) in Egypt dealing with Military nurses showed that half of them were in the age category $20-30$ years $(50.0 \%)$ with statistically significant difference as regard their age categories $(\mathrm{P}<0.05)$. Regarding the nursing Staff $75.0 \%$ were females; with a highly significant difference $(\mathrm{P}<0.01)$, of whom $35 \%$ were officers and $65 \%$ were sergeants. A total of $25.0 \%$ were University graduates, $22.5 \%$ carried Technical Institute of Nursing 
and 52.5\% had Secondary School Nursing Diploma. Their experience years were $<$ 5years $(25.0 \%), 5-<10$ years $(52.5 \%)$ and $>10$ years $(22.5 \%)$, in departments of Internal Medicine (40\%), Surgery (35\%) and Emergency/ ICU (25.0\%).

El Bahnasawy et al. (2014) in Egypt reported that $24 \%$ of the nurses were married, seventy six $(76 \%)$ single, with mean age of $21.6 \pm 5,90 \%$ had diploma in nursing but $10 \%$ undergraduate students.

In the present study, $56 \%$ of the nurses had satisfactory knowledge level as regard nosocomial parasites, without significant difference

Khudair and Raza (2013) in Qatar found that highly significant relation between nurse's level of knowledge and their age. Baja et al, (2014) in Germany found that more the age and experience better the knowledge, and that positive effect of educational degree on the level of knowledge and percent of knowledge improvement after educational session held in studied hospitals.

Abroad many authors worldwide reported nosocomial or hospital acquired parasites. The following were selected representative group. Lettau (1991) in USA stated that both the standard of hygiene and sanitation prevalent in hospitals and the rarity of parasitic diseases compared to viral, bacterial, and fungal infections, reduce the hazard of nosocomial acquisition of parasites to relatively trivial levels, he added that the nosocomial acquisition of parasites might be somewhat underappreciated because the incubation period for clinical illness may be days to weeks and thus a hospital-acquired parasites night not be recognized as such, particularly if the parasite is endemic locally. However, the exact magnitude of the problem in tropical hospitals was also more difficult to determine. Moro et al. (2002) in Italy described nosocomial transmission of malaria from patient to patient via blood exposure. Alweis et al. (2004) in USA described the transmission of Plasmodium falciparum malaria from a patient to a healthcare worker and then from the healthcare worker to another patient. They concluded that the nurse who had acquired falciparum malaria via needle-stick subsequently transmitted malaria to another patient via a break in standard precautions. Sugiyama et al. (2006) in Japan examined whether medical staff were infected with Strongyloides stercolaris through exposure to the body substances of a patient with disseminated strongyloidiasis, who excreted a large number of $S$. stercolaris in the respiratory secretions and stool-like excretions from a nasogastric tube. They concluded that adherence to the standard precautions is sufficient for preventing the nosocomial transmission of this organism. Vorou et al. (2007) in Greece reported that factors facilitating the development of hospital-acquired scabies and nosocomial epidemics were: poor knowledge of scabies epidemiology, unfamiliarity of healthcare workers with atypical presentations, long incubation period, diagnostic delay and incomplete monitoring.

Sanad and Al-Malki (2007) in Saudi Arabia reported that Cryptosporidium infection rates of $84 \% \& 74.3 \%$ were in patients receiving I.S. drugs for organ transplantation and malignancy respectively. In all patients, the highest infection rate (84\%) was among age group 16-40 years while the least $(35.3 \%)$ was among the infants $<2$ years $(\mathrm{P}<0.001)$. Infections in males $(73.9 \%)$ was significantly $(\mathrm{P}<0.05)$ higher than females (62.6\%). This high prevalence rate revealed the first reported for the cryptosporidiosis among immune-compromised Saudis, indicating the presence of infection source(s) (nosocomial), and thus, transmission in Saudi Arabia.

Bellanger et al. (2008) in France described a case of nosocomial infestation with D. gallinae from an abandoned pigeon nest suspended on the front wall of the Hôpital Henri Mondor near a window. Khurana et al. (2008) in India stated that intestinal infection is still an important public health problem in developing countries like India. Food 
handlers might be infected by a wide range of entero-pathogens and Giardia was the most common parasite was implicated in transmission of many infections to the public in the community and to patients in hospitals. During the year 2001, they reported an outbreak of ETEC in the neonatal ICU, Advanced Pediatric Centre, and Primer, which was traced back to a food handler involved in the preparation of the milk feed.

Lee et al. (2011) in Taiwan reported a case of nasal myiasis caused by Sarcophaga spp., noted during hospitalization. The patient underwent coronary arterial bypass surgery and was then mechanically ventilated by means of a nasotracheal tube for the next 8 days.

Góralska aqnd Kurnatowski (2013) in Europe stated that nosocomial infections represent an increasing threat to public health. They added that most studies of te incidence of nosocomial infections ignore parasitic infections. Based on data from 1,265 intensive care units in 75 countries, it was found that the proportion of parasites in nosocomial infections was $0.48 \%$ overall, and $0.25 \%$ in Western Europe. An analysis of the available literature indicates an increase in the number of hospital parasitoses.

The current results indicated that, most of the respondents had negative attitudes toward food safety measures, that is may be due to poor awareness of this aspect. This result is similar to the study of Buccheri et al. (2007) to evaluate knowledge, attitudes and practice concerning food safety of the nursing staff, the survey revealed that a general positive attitudes toward safe storage practice but respondents fared worse when they were asked about cross contamination, refreezing and handling unwrapped food with cuts or abrasions on hand (Buccheri et al., 2007).

In the present study, most participants had negative compliance scale to infection control measures with significant lower score for the procurement, storage and preparation of raw material followed by personal hygiene $(\mathrm{p}<0.05)$. Almanza et al. (2007) in
USA determined typical handling practices of home-delivered meals, and provide appropriate handling instructions to reduce the risk of foodborne illness by improving consumer handling of home-delivered meals. They reported advantage of educational program on the improvement of base line knowledge and attitude toward heat exposure health hazard. Gardner (2014) in USA studied the lived experience of nurse educators and the characteristics, traits, practices, and experiences that influenced their development and competence. He declared that the nurse and nurse faculty shortage resulted in a continuous demand for new nurse educators. Chronister (2014) in USA evaluated whether an educational segment monitoring could be improved with focused education. Saleh et al. (2014) in Egypt found that 60\% of participant nurses have positive compliance scale to infection control measures with significant higher score for precautions for BBPs prevention $(\mathrm{P}<0.05)$. El Bahnasawy et al. (2014) reported that the implementation of the educational program for Military Nursing Staff on selected infectious disease disasters at Egyptian Eastern Border was effective. They added that the intervention showed statistically significant improvements in nursing staff knowledge, at the immediate post intervention phase, and after three months post-test phase. They concluded the statistically significant strong positive correlations among staff nurse knowledge and scores, multivariate analysis indicated that nursing staff knowledge were positive. El Bahnasawy et al. (2014) reported that nurses $(96.0 \%)$ were willing to attend educational program about health hazard during pilgrim mostly to improve practice $(56.0 \%)$ and raise awareness (44.0\%), with significant improvement regarding adequate knowledge after program implementation. They added that the most needed topics during Hajj were prevention \& vaccination $(26.0 \%)$.

In the present study, nurses in age group > 30 years got the highest total mean \% com- 
pliance score than other age groups. Nurses carrying bachelor degree of nursing got the highest total mean \% compliance score; also those with work experience $>10$ years have got the highest total mean $\%$ attitude score. There was a statistically significant difference between total mean compliance score according to education and years of experience $(\mathrm{P}<0.05)$.

In this study, there was a significant relation between nurses' knowledge and their previous training, while there was no significant relation between nurses' previous training and their attitudes and practice. That is may be because only $40 \%$ of the nurses were able to attend infection control educational program and none of them (zero \%) could attend courses related to food safety or parasites' infection control. This result is inagreement with a number of studies which have demonstrated a lack of correlation between food hygient training and improvements in food hygiene behavior (Ansari-Lari et al, 2009; Sanlier and Turkmen, 2010).

On the other hand, the epidemiology of (Soil Transmitted Parasites or parasites or in not well washed green salad) STP infections is influenced by several keys determinants, including the environment, population heterogeneity, age, household clustering, genetics and polyparasitism (Hotez et al, 2008). Adequate warmth and moisture are key for infection with one or more STH species in Africa in 2005 and considerable geographical variation in the occurrence of STH infections (Broker et al, 2009). Several epidemiological studies were done on STPs in Egypt and worldwide, however most of these studies were based on stool examination with no direct estimation of parasitic burden in soil samples

Regarding Egyptian Governorates, several reports detected different STPs with higher prevalence rates $(53.4 \%$ and $92.5 \%)$ in soil samples collected from agricultural villages in Talkha center (Hanafi et al, 1987) and in Manoura City of El-Dakahlia Governorate (El-Beshbishi et al, 2005).
Kishk and Allam (2000) in Alexandria found prevalence rate of soil contamination with helminthes to be $38.33 \%$. Also, Hussien et al. (2010) in Alexandria reported that the soil contamination with different parasites was $31.9 \%$ (67 out of 210 soil samples). The soil in the different districts was found to be contaminated with 18 different parasites of medical and veterinary importance that belong to: helminthes $(55 \%)$, protozoa (34\%) and arthropods (4\%).

El Zawawy et al. (2010) in Egypt investigated the efficacy of sodium dichloroisocyanurate $(\mathrm{NaDCC})$ on the infective stages of common food-borne intestinal protozoa; $E$. histolytica, G. lamblia, Cryptosporidium parvum, Cyclospora and Microsporidia; beside its effect on raw green vegetables and fruits. Results revealed significant reductions in viability and infectivity of all examined parasites indicating their susceptibility to the NaDCC. Relative variations in susceptibility were revealed; E. histolytica and G. lamblia were most susceptible (100\% reduction) followed by Microsporidia then C. parvum and Cyclospora. NaDCC did not affect the consistency, color, taste or flavor of raw green vegetables and fruits. The proved efficacy of NaDCC, in cheap and convenient dry tablet form, makes it a promising tool in decontaminating raw vegetables and fruits from food-borne protozoan parasites at household and restaurant levels as well as in catering and fresh produce industry. It is also recommended for disinfection of food preparation surfaces and equipment.

El Fakahany et al. (2013) in Qalyoubia Governorate conducted a survey at Benha City (100 soil samples) and Shiblanga village (100 soil samples) representing the urban and rural areas. Geo-parasites were investigated in-doors, around houses, in the fields and the streets from both areas. The results showed that $86 / 200$ soil samples were contaminated with different parasites, the prevalence rate of $43 \%$. Soil samples from Shiblanga village showed higher level of parasitic contamination (56\%) and Benha 
City showed a lower level of contamination by different parasites (30\%). Soil samples obtained from Manshiet El-Nour district, Benha revealed the highest level of parasitic contamination. Parasites were eggs of $H$. nana, $H$. diminuta, A. lumbricoides, Toxocara spp., Ancylostoma duodenale larvae, E. histolytica cysts, Cryptosporidium parvum oocysts and $T$. gondii oocysts. The parasitic prevalence among Egyptian households stool samples in Qualyobia G. was 30.5\%, containing $H$. nana eggs, $A$. lumbricoides, $E$. vermicularis eggs, A. duodenale, E. histolytica cysts, C. parvum oocysts, B. hominis cysts and Isospora belli oocysts. There was no statistically significant difference in sex regarding infection. School age group was the commonest infected one (59\%). Parasites detected were 10/50 houses. A. duodenale ova were detected in soil of 4 houses with the same parasite in households' stools, $A$. lumbricoides eggs were detected in four houses with the same parasite in house-holds stools and E. histolytica cysts were detected in two houses with the same parasite in households stools.

The WHO (2006) reported that prevention of STP on green vegetable or by well washing of green salad vegetables protect man from many parasitic infections

Abroad, regarding STPs, Ortega et al. (1997) in Peru detected oocysts of C. parvum and Cyclospora cayetanensis from salad vegetables collected in markets of an endemic region. Ulukanligil et al. (2001) in Turkey reported the rate of soil contamination with parasites to be $9.4 \%$. Motazedian et al. (2006) in Iran reported $84.4 \%$

Gourabathini et al. (2008) in Italy reported that the presence of protozoa on leafy vegetables and their sequestration of enteric bacteria in vesicles indicate that they might play an important role in the ecology of human pathogens on produce.

Paul et al. (2012) in England stated that Solar ultraviolet (UV)-B radiation (280-315 $\mathrm{nm}$ ) has a wide range of effects on terrestrial ecosystems, yet the understanding of how
UV-B influences the complex interactions of plants with pest, pathogen and related microorganisms remains limited.

Ranjbar-Bahadori et al. (2013) in Tehran reported that the vegetables in the farms were contaminated with Cryptosporidium oocysts that infected man on eating underwashed green salad.

Now days, the public health nurse is, assistance to the process of solving one's health, identifying health issues based on a community, using systematic measures which lead to prevention, and aiming at public responsibility. The daily activity of Nurses including Occupational Health Nurses (OHNs) was based on the theory and technology of "empowerment". In promoting the employer-and-employees independent Occupational Safety and Health Activity, the OHN's professional specialty of "empowerment" can play an important role (Ikeda, 2013). Worldwide, many occupational health services are provided by occupational health nurses independently or in collaboration with other disciplines' professionals. The services may be health protection, health promotion, or both, and are designed to reduce health risks, support productivity, improve workers' quality of life, and be costeffective (Rogers et al, 2014).

On the other hand, nosocomial arthropodblooding sucking as mosquitoes, lice, bugs and ticks (Morsy, 2012) as well as nosocomial myiasis (Morsy, 2014) is another issue of infections' control nurse.

\section{Conclusion}

This descriptive study highlighted the importance of raw fruits and vegetables as the potential source for intestinal nosocomial parasites. Fruits and vegetables contamination with the parasites poses health risk to the consumers if consumed without proper cleaning (green salad) and/or cooking.

Nurses $(56 \%)$ had satisfactory knowledge level $(40 \%)$ got pass and $16 \%$ got good scores) while $44.0 \%$ failed with high significant difference $(\mathrm{P}<0.01)$. There was a significant difference between total mean know- 
ledge \% score according to sex, education, previous training courses and marital status $(\mathrm{P}<0.05)$. Also, 54\% had positive attitude towards nosocomial parasite control and prevention without significant difference between all items $(\mathrm{P}>0.05)$, with significant difference between total mean attitude \% score according to sex, education and marital status $(\mathrm{P}<0.05)$.

Nurses $(60 \%)$ had inappropriate practice of the infection control measures with significant lower score for the procurement, storage and preparation of raw food materials followed by personal hygiene $(p<0.05)$. There was significant difference between the total mean practice score according to education and years of experience $(\mathrm{P}<0.05)$

\section{Recommendations}

Food is at risk in all areas where it is stored, prepared, transported and served. Apart from physician all health care staff are involved in the storage, preparation, transportation and serving of food need training in food hygiene practices to minimize the transmission of gastro-intestinal infections to patients. Perhaps the nosocomial endo-parasites were not dealt with in Egypt.

Nevertheless, the prevention of contamination remains the most effective way of reducing food borne parasitic infection. A comprehensive health education should be given to vendors and farmers of fruits and vegetables and to the general population on the health risks associated with consumption of contaminated raw fruits and/or vegetables. The consumers should always observe the basic principle of food and personal hygiene, that is, thorough washing of the fruits and vegetables before eating and washing hands before meal, especial concern is for health professionals.

Nurses in all roles and settings can demonstrate leadership in infection prevention and control by using their knowledge, skill and judgment to initiate appropriate and immediate infection control procedures. Food handlers are frequently nurses, involved in food operations and supervision functions without the preliminary and continuous food safety training and education courses that the European and national legislations mandate for professional food handlers. Frequent awareness of foodborne disease hazards and prevention and control measures is a must

Now, is it mandatory to have food safety nurse? Her job description is to ensure:

1- Wash patient hands before touching food, and always after using the toilet. 2- Cover cuts and sores with waterproof dressings. 3Ensure that the food is palatable and nutritious as well as safe. 4- Prohibited smoking, in food-rooms and never cough or sneeze over food. 5- Keep kitchen equipment and utensils. 6- Keep food clean, covered and either cold or piping or piping hot, separate raw and cooked food. 7- Prevent visitors and patients allowed entry into ward kitchens or the use of any facilities. 8- Report any symptoms of food ill-health e.g. rashes, diarrhea, vomiting, upper respiratory tract and septic infections to their managers, with details to the occupational health department for guidance ward kitchens to be used by authorized staff.

\section{References}

Alabaster, E, 2007: Involving students in the challenges of caring for older people. Nurs. Older People 19, 6:23-8.

Almanza, BA, Namkung, Y, Ismail, JA, Nelson, D, 2007: Clients' safe food-handling knowledge \& risk behavior in a home-delivered meal program. J. Am. Diet Assoc. 107, 5:816-21.

Alweis, RL, Di-Rosario, K, Conidi, G, Kain, KC, Olans, R, et al, 2004: Serial nosocomial transmission of Plasmodium falciparum malaria from patient to nurse to patient. Infect. Control Hosp. Epidemiol. 25, 1:55-9.

Ansari-Lari, M, Soodbakhsh S, Lakzadeh L, 2009: knowledge, attitudes and practice of workers on food hygiene practice in meat processing plants in Fars, Iran. Food Cont. 21:26.

Ashton, S, 2014: Leadership walk-rounds in mental health care. Nurs. Times 110, 23:21-3.

Baja, J, Welker, A, Beck, G, Schleppers, A, Fischer, M, et al, 2014: Professional image of anesthetists in the general public. Influence of provision of information and previous experience with discipline. Anesthesist 63, 2:114-21 
Bellanger, AP, Bories, C, Foulet, F, Bretagne, S, Botterel, F, 2008: Nosocomial dermatitis caused by Dermanyssus gallinae. Infect. Control Hosp. Epidemiol. 29, 3:282-3.

Bertrand, B, Livingston-Bowen, C, Duffrin, C, Mann, A, 2014: ACE inhibitors and potassium foods-nurses' knowledge. Int. J. Hlth. Care Qual. Assur. 27, 1:54-64.

Buccheri, C, Casuccio A, Giammanco S, Giammanco M, La Guardia M, Mammina, C, 2007: Food safety in hospital: knowledge, attitudes and practices of nursing staff of two hospitals in Sicily, Italy. BMC Hlth. Serv. Res. 7:4552.

Chronister, C, 2014: Improving nurses' knowledge of continuous ST-segment monitoring. AACN Adv. Crit. Care 25, 2:104-13.

El Bahnasawy, MM, El Meniawy, NZA, Morsy, TA, 2014b: An interventional program for nursing staff on selected mass gathering infectious diseases at Hajj. J. Egypt. Soc. Parasitol. 44, 2:405-24.

El Bahnasawy, MM, Labib, NA, Abdel-Fattah, MA, Inrahim, AMA, Morsy, TA, 2014: Selected infectious disease disasters for nursing staff training at Egyptian Eastern Border. J. Egypt. Soc. Parasitol. 44, 1:41-54.

El Beshbishi, SN, Abdel-Magied, AA, El-Nahas, HA, Azab, MS, El-Shazly, AM, Morsy, ATA, 2005: Geoparasites in rural Dakahlia governorate, a preliminary based study for development of the community-based intervention programs. J. Egypt. Soc. Parasitol. 35, 3:105170.

El Fakahany, AF, Younis, MS, Ali, EA, ElGhareeb, AS, Omar, RS, 2013: Soil transmitted parasites in Qualyobia Governorate, Egypt. J. Egypt. Soc. Parasitol. 43, 2:527-36.

EI Jardali, F, Murray, SF, Dimassi, H, Jamal, D, Abualrub, R, et al, 2013: Intention to stay of nurses in current posts in difficult-to-staff areas of Yemen, Jordan, Lebanon and Qatar: a crosssectional study. Int. J. Nurs. Stud. 50, 11:148194.

El Kady, N, Ramzy, I, Hanan, HA, Haleem, A, El-Bahnasawy, MM, 2011: Echoguided pair technique in diagnosis and treatment of abdominal hydatid cystic disease in Egyptian pattients: clinical and ultrasonographic follow up. J. Egypt. Soc. Parasitol. 41, 3:527-42.

El-Shazly, AM, Mowafy, N, Soliman, M, ElBendary, M, Morsy, AT, et al, 2004: Egyptian genotyping of Giardia lamblia. J. Egypt. Soc. Parasitol. 34, 1:265-80.

El Shazly, AM, Elsheikha, HM, Soltan, DM, Mohammad, KhA, Morsy, TA, 2007: Protozoal pollution of surface water sources in Dakahlia Governorate, Egypt. J. Egypt. Soc. Parasitol. 37, 1:5-64.

El-Sibaei, MM, Rifaat, MM, Hameed, DM, El-Din, HM, 2003: Nosocomial sources of cryptosporoidial infection in newly admitted patients in Ain Shams University Pediatric Hospital. J. Egypt. Soc. Parasitol. 33, 1:177-18

EI Zawawy, LA, El-Said, D, Ali, SM, Fathy, FM, 2010: Disinfection efficacy of sodium dichloroisocyanurate (NADCC) against common food-borne intestinal protozoa. J. Egypt. Soc. Parasitol. 40, 1:165-85.

Gardner, SS, 2014: From learning to teach to teaching effectiveness: nurse educators describe their experiences. Nurs. Educ. Perspect. 35, 2: 106-11.

Goralska, K, Kurnatowski, P, 2013: Parasites as etiological factors of nosocomial infections. Ann. Parasitol. 59, 1:3-11

Gourabathini, P, Brandl, MT, Redding, KS, Gunderson, JH, Berk, SG, 2008: Interactions between food-borne pathogens and protozoa isolated from lettuce and spinach. Appl. Environ. Microbiol. 74, 8:2518-25.

Hanafi, FZ, Yousseff, ME, Abdel-Wahab FM, 1987: Soil as vehicle of parasitic infection to inhabitants of Talkha, Dakahlia Governorate. J. Egypt. Soc. Parasitol. 17, 1:135-45.

Hotez, PJ, Savioli, L, Fenwick, A, 2012: Neglected tropical diseases of the Middle East and North Africa: review of their prevalence, distribution, and opportunities for control. PLoS Negl. Trop. Dis. 6(2):e1475. doi: 10.1371/ journal.pntd. 0001475.

Hussein, NMF, El Kerdany, EDH, Allam, SF, El Zawawy, LA, 2010: A study of medically important soil trans-mitted parasites in Alexandria. Med. Parasitol. 1258:80-90.

Ikeda, T, 2013: The role and future task of the occupational health nurse. J. UOEH. 35:S59-66. Khudair, IF, Raza, SA, 2013: Measuring patients' satisfaction with pharmaceutical services at a public hospital in Qatar. Int. J. Hlth. Care Qual. Assur. 26, 5:398-419.

Khurana. S, Taneja, N, Thapar, R, Sharma, M, Malla, N, 2008: Intestinal bacterial and parasitic infections among food handlers in a ter- 
tiary care hospital of North India. Trop. Gastroenterol. 29, 4:207-9.

Kishk, NA, Allam, SR, 2000: Prevalence of intestinal helminthes among preschool children and its relation to soil contamination in Alexandria. J. Med. Res. Inst. 21:181-92.

Kouchak, F, Askarian, M, 2012: Nosocomial Infections: The definition Criteria. Iran. J. Med. Sci. 37, 2: 72-3.

Lazarević, K, Stojanović, D, Bogdanović, D, Dolićanin, Z, 2013: Hygiene training of food handlers in hospital settings: important factor in the prevention of nosocomial infections. Cent. Eur. J. Publ. Hlth. 21, 3:146-9.

Leach, DC, 2014: Transcendent professionalism: keeping promises and living the questions. Acad. Med. 89, 5:699-701.

Lee, YT, Chen, TL, Lin, YC, Fung, CP, Cho, W, 2011: Nosocomial nasal myiasis in an intubated patient. J. Chin. Med. Assoc. 74, 8:369-71. Lettau LA, 1991: Nosocomial transmission and infection control aspects of parasitic and ectoparasitic diseases: Part III. Ectoparasites/summary and conclusions. Infect. Control Hosp. Epidemiol. 12, 3:179-85.

Marecki, M, Heeb, K, Zitka, W, 1997: Protozoan infection in the perinatal period. J. Perinat. Neonatal Nurs. 11, 1:21-33.

Moro, ML, Romi, R, Severini, C, Casadio, G P, Sarta, G, et al, 2002: Patient-to-patient transmission of nosocomial malaria in Italy. Infect. Control Hosp. Epidemiol. 23, 6:338-41.

Mutale, W, Ayles, H, Bond, V, Mwanamwenge, MT, Balabanova, D, 2013: Measuring health workers' motivation in rural health facilities: baseline results from three study districts in Zambia. Hum. Resour. Hlth. Feb 21;11(1):8. doi: 10.1186/1478-4491-11-8.

Ortega, YR, Roxas, CR, Gilman, RH, Miller, NJ, Cabrera, L, et al, 1997: Isolation of Cryptosporidium parvum and Cyclospora cayetanensis from vegetables collected in markets of an endemic region in Peru. Amer. J. Trop. Med. Hyg. 57: 683-6.

Paul, ND, Moore, JP, McPherson, M, Lambourne, C, Croft, P, et al, 2012: Ecological responses to UV radiation: interactions between the biological effects of UV on plants and on associated organisms. Physiol. Plant. 145, 4:565-81.

Ranjbar-Bahadori, Sh, Mostoophi, A, Shemshadi, B, 2013: Study on Cryptosporidium conraminatin in vegetables farms around Tehran Trop. Bio-med. 30, 2:193-8.
Rashed, AA, Khalil, HHM, Morsy, ATA, 2010: Zoonotic ectopic fascioliasis: review and discussion. J. Egypt. Soc. Parasitol. 40, 3:591600.

Rogers, B, Kono, K, Marziale, MH, Peurala, M, Radford, J, et al, 2014: International survey of occupational health nurses' roles in multidisciplinary teamwork in occupational health services. Workplace Hlth, Saf. 62, 7:274-81.

Saleh, AMA, Ali, HA, Ahmed, SAM, Hosny, SM, Morsy, TA, 2014: Screening of Toxoplasma gondii infection among childbearing age females and assessment of nurses' role in prevention and control of toxoplasmosis. JESP 44, 2:329-42.

Sanad, MM, Al-Malki, JS, 2007: Cryptosporidiosis among immuno-compromised patients in Saudi Arabia. J. Egypt. Soc. Parasitol. 37, 2: S765-74.

Sanlier, N, Bilici, S, Celik, B, Memis, E, 2012: food safety knowledge and practice of nursing students, Ital. J. Food Sci. 24, 1:1-8.

Sanlier, N, Turkman, I, 2010: perception of hygiene among staff working in food companies. Res. J. Med. Sci.4, 3:231

Sugiyama, K, Hasegawa, Y, Nagasawa, T, Hitomi, S, 2006: Exposure of medical staff to Strongyloides stercolaris from a patient with disseminated strongyloidiasis. J. Infect. Chemother. 12, 4:217-9.

Ulukanligil, M, Seyrek,A, Aslan, G, Ozbilge, H, Atay, S, 2001: Environmental pollution with soil-transmitted helminthes in Sanliurfa, Turkey. Mem. Inst. Oswaldo Gruz. 96, 7:903-9.

Vincent, JL, Rello, J, Marshall, J, Silva, E, Anzueto, A, et al, 2009: International study of the prevalence and outcomes of infection in intensive care units. J. Amer. Med. Assoc. 302: 2323-9.

Vorou, R, Remoudaki, H, Maltezou, H, 2007: Nosocomial scabies. J. Hosp. Infect. 65, 1:9-14.

Weinstein, R, 2004: Hospital-acquired infections. In: Kasper DL, Braunwald E, Fauci AS, Hauser SL, Longo DL, Jameson JL, Isselbacher KJ, eds. Harrison's Principles of Internal Medicine. $16^{\text {th }}$ ed. New York: McGraw Hill.

WHO, 2006: Preventive Chemotherapy in $\mathrm{Hu}-$ man Helminthiasis: Coordinated Use of Anthelminthic Drugs in Control Interventions: A Manu ual for Health Professionals and Program Managers, Geneva. 